\section{Vaginal Birth Related Perineal Traumas and the Importance of Experimental Trainings}

\author{
Hülya Erbaba ${ }^{1}$, Przemyslaw Ciesielski ${ }^{2}$
}

\begin{abstract}
Perineal trauma caused by vaginal delivery is a problem that can occur in various ways from small lacerations to anal sphincter injury and one that negatively affects the quality of life of the woman. Specialists or midwives liable at perineal trauma repair are required to complete the intervention training for perineal trauma before their clinical practice and increase their skills with in-service training. The most important training materials used in the trainings organized for this purpose are the models consisting of materials that have very close properties to the actual tissues and organs. The aim of this study is to reveal the importance of skills training given to individuals responsible for repairing perineal traumas and to evaluate the effect of different application examples in this field.
\end{abstract}

Keywords: perineal traumas, experimental trainings, animal and artificial tissue

\section{Correspondence: \\ Hülya Erbaba}

Address: Beykent University, Istanbul, Turkey

Email: hulyaerbaba3@hotmail.com
Received: 27.11.2019,

Accepted: 18.12.2019

https://doi.org/10.5799/jcei/7589

\section{INTRODUCTION}

Perineal trauma seen in original births (PT) can lead to short- and long-term complications for the mother. Symptoms such as perineal pain and dyspareunia due to perineal trauma significantly reduce the quality of life of women [1]. Perineal traumas may develop to different degrees. Studies on natural childbirth found that $85 \%$ of women experience a variety of perineal traumas. In addition these traumas have been occurred $0.6-11 \%$ of all births result in third or fourth degree tears [2], \%77 second degree tears [3]. In another study, the incidence of PT was found to be $84.3 \%$. Ninety-five percent of the primiparous women and $43.9 \%$ of the multiparous women had an episiotomy [4]. In normal vaginal births, severe laceration rates for all parities are reported as $2.2 \%$, while all episiotomy rates vary from country to country. In New Zealand, for example, episiotomy rates are much lower than in many other countries. The Midwifery and Mothers Support Organization (MMSO) in this country maintains a good database in which midwives can provide statistics on all births they have delivered in and out of the hospital. One of the most important factors in the expression of episiotomy rates is that the evidence-based records are well maintained. Based on data from 987 midwives registered with MMSO in 2013, the rate of episiotomy in normal vaginal deliveries for all parities was reported as $5.9 \%$. According to Kalichman and Bick, $2 / 3$ of all lacerations require repair $[5,6]$.

The question of how to reduce PTs at birth is a subject that is always on the agenda of obstetricians and midwives. For this reason, many roadmaps have been tried to be prepared by the experts to take precautions. One of them is the recommendations regarded as "Four core themes". The recommendations that have emerged 21 Irish and New Zealander expert midwives' qualitative exploration of the skills used to protect the perineum in spontaneous vaginal delivery are; "1-Calm, controlled delivery", "2-Position and techniques in the early period of the second stage", "3-Hands on or hands off? Evaluate according to the situation" and "4-Slow down, slow down the baby and blow it up. (Relax in the crowning phase, breathe, let the head slowly stretch the perineum, let the shoulders turn, take the baby slowly). Midwives using this method have achieved in nulliparous women $3.9 \%$ episiotomy, 
$59 \%$ sutureless delivery and $1.08 \%$ suture for severe lacerations [7].

In addition to new ideas, some studies have been conducted to learn from past experiences. For example, a study conducted with 70 midwives who delivered at a university hospital in Norway with 4800 births per year examined midwifery skills, past experiences and current considerations to prevent and improve PTs. At the end of the study, midwives stated that perineal trauma is a complex process that varies from individual to individual and is affected by different factors; that each birth has a distinct atmosphere; that the intervention to the trauma requires professional experience; that meticulous recording of the incidents would reveal the real situation and they argued that forwardly sharing of both positive and negative ${ }^{1}$ experiences related to $\mathrm{PT}$ repair by doctors and midwives is important for the development of professional midwifery [8].

In order to prevent $\mathrm{PT}$, studies have also been conducted to associate perineal trauma with the ability to lead birth. In a study which evaluated the obstetric outcomes of births after pregnancies followed up by obstetricians and midwives it was observed that the rates of episiotomy was lower in the pregnant patients followed up by midwives than by obstetricians [9]. When the vaginal deliveries under the leadership of midwives was compared with the delivery management under the leadership of obstetricians, a decrease in use of pain killers and oxytocin and a decrease in membrane tears and episiotomy rates was observed in the births directed by midwives [10]. While despite some studies of Scandinavian countries covering the years 1994-1998 held midwifery techniques responsible for the increase in PT in recent years, these claims have not been proved [8].

On the other hand, a number of studies that allowed for self-criticisms approached the subject from a different angle and questioned the adequacy of the professional experience, surgical experience and in-service training of the obstetricians and midwives in relation to the interventions to perineal traumas and sought a solution to the problem from these perspectives [11]. These studies showed that despite the high percentage of PT occurrence, the majority of obstetricsgynecology students and midwives were not adequately prepared to use their surgical skills independently, as they did not gain effective clinical experience during school and internship periods $[8,12]$.

Facilitating the gaining of skills related to the repair of PTs which directly affect female health through short- and long-term complications will result in fewer women experiencing trauma associated with labor. For this reason, it is important that both the upcoming students and those already working in the delivery rooms increase their practical experience. Today, advanced and non-advanced simulations that help develop clinical skills, especially "basic skill part task trainers" which are regarded as low fidelity/ highly invasive simulators, simulate real objects especially parts of the body or an organ. These inexpensive models enable the development of basic psychomotor, operational and technical skills [13]. The effects of the use of simulative methods on education can be explained with learning theories such as Adult Learning Theory (Knowles, Malcolm Experience Based (Experiential) Learning Theory (David A. Kolb, John Dewey), Skill Gain Theory (Patricia Benner) and Clinical Decision Making Model (Cristine A. Tanner) [14].

Practical trainings such as PT, episiotomy and suturing can be performed in school laboratories and clinics by using synthetic sponges or the tongues/tissues of some animals due to their easy access and cost effectiveness. Animal-based anatomical models of childbirth-induced perineal tear are an important element of the physicians' practical training [15].

Thus, students can find the opportunity to work on the tissues closest to the female reproductive organ anatomy before touching the real patient [16]. For this purpose, a study by Ciesielski et al. evaluate the efficacy of a model prepared by them from animal tissues (pig tongue and intestines) in the training on reconstruction of $3 \mathrm{rd}$ and 4 th degree lacerations that occur during delivery (Figure 1). At the end of the study, $85 \%$ of the participants reported that this model was very close to the natural perineum tissues and 95\% of the participants reported that their training on the model was satisfactory [17].

Another study measures the students' self-confidence after training on performing episiotomy procedures on sponge perineum and perineum prepared from animal tongue (beef tounge) by Güler et al. intended for midwifery students (Figure 2). At the end of the study, both groups were able to apply all the processes, but the self confidence of the students who were trained in the calf tongue model was reported to be statistically ( $\mathrm{p}<0.05$ ), higher than the sponge group [18].

However, as a result of the innovation studies that have rapidly taken place in the medical field with the development of technology, alternative, economical, easily accessible and facilitating training materials that can be obtained in mass production are being developed.

Trainings provided with this type of simulative materials similar to human anatomy, provide a safe and comfortable environment for trainees to make inferences from their mistakes [13]. One of the studies on such products is a silicone perineum model which is standardized for use in laceration repair rehearsals and is reported to be more coherent with the anatomy (Figure 3) [19]. The silicone perineum is made with a technological tool that works with the logic of a printer called a 3D printer, transforming products from a digital medium into a three-dimensional 

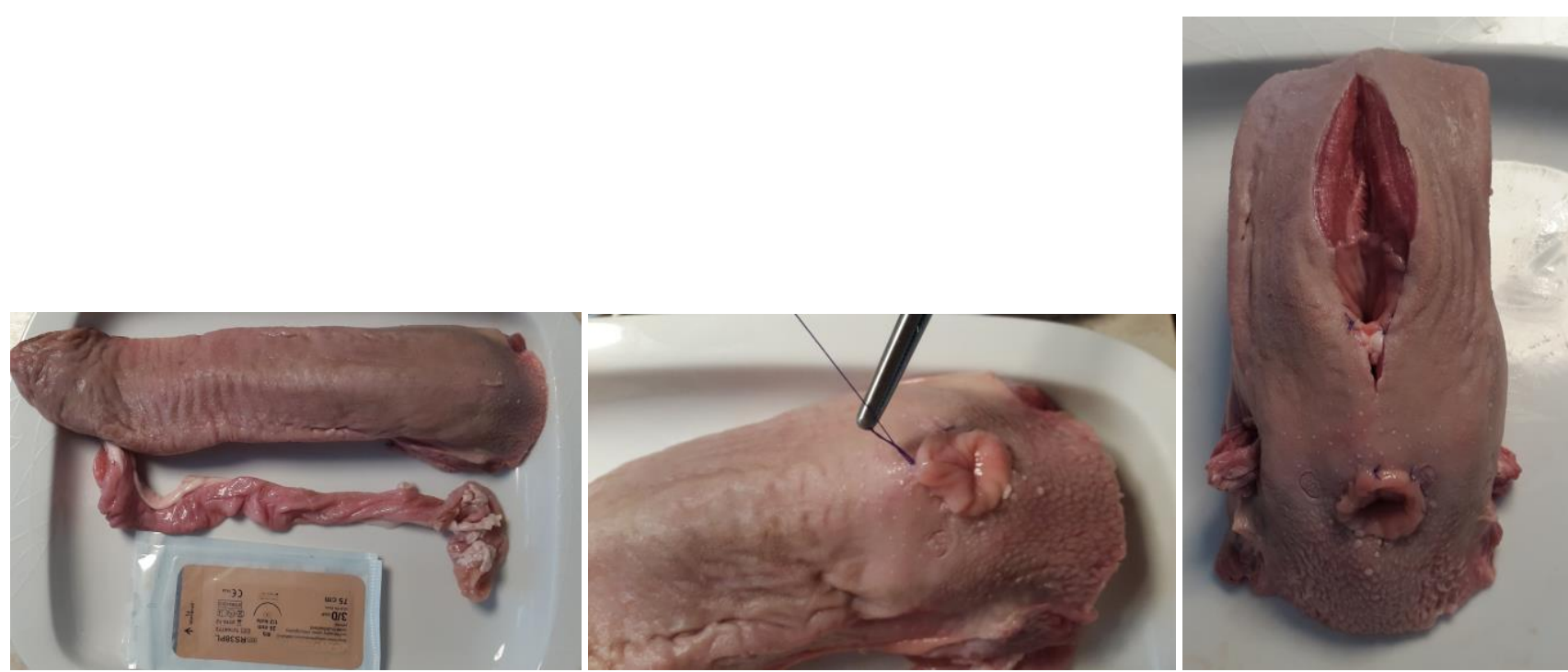

Figure 1. Perineal laceration studies on porchine tounge model
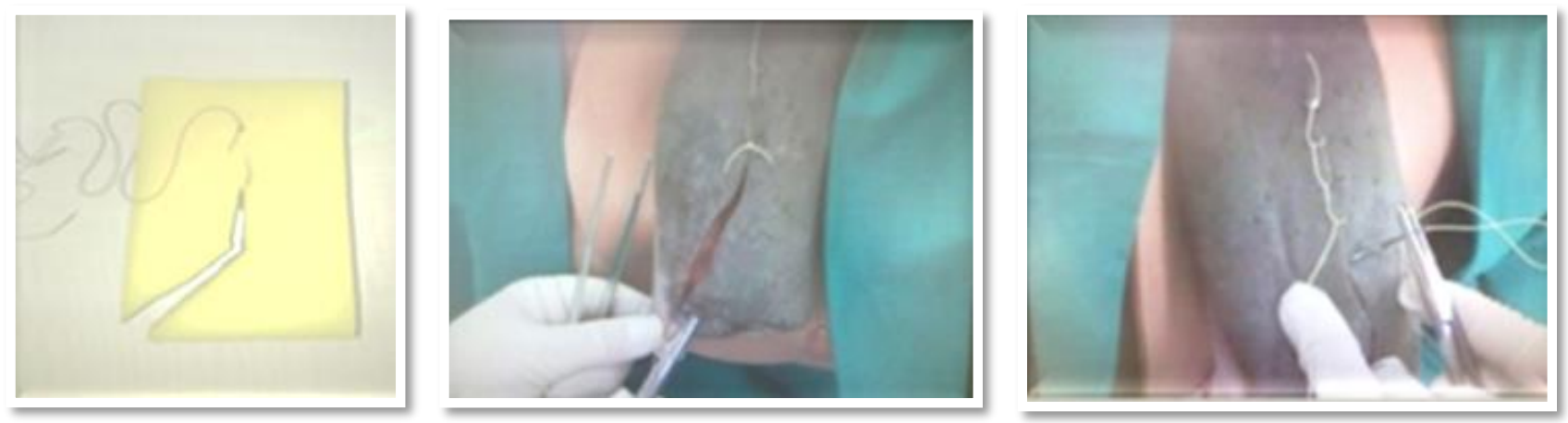

Figure 2. Perineal laceration studies on beef tounge model
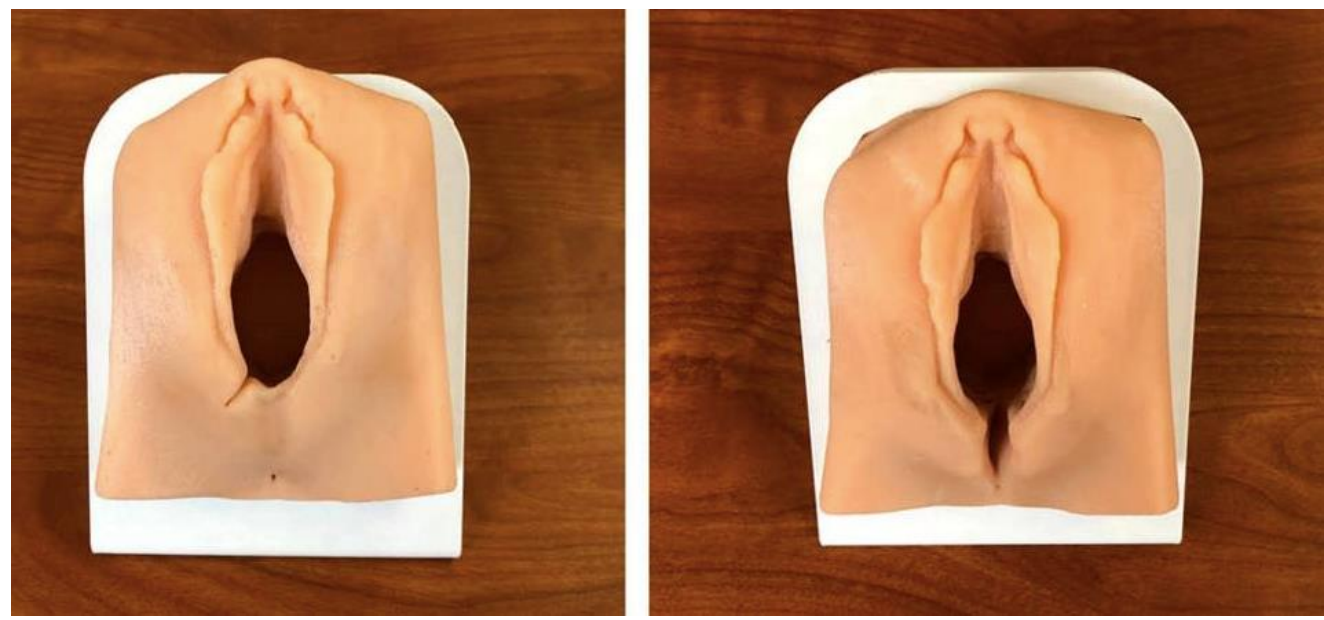

Figure 3. Perineal laceration studies on 3D perineal model

solid object [20]. Simulation training with 3D modeling has been for a long while used in various medical fields such as Otorhinolaryngology, Orthopedics, Cardiology, Plastic and Reconstructive Surgery, Ophthalmology, Urology, Neurosurgery, Cardiovascular Surgery, General Surgery and Anaesthesiology [21]. At the end of the silicone perineum model study; repairs on silicone perineum, including fourth degree laceration, have been reported to be a cost-effective method to teach and maintain perineal repair skills more accurately than contrasting models such as cattle tongues [20].

Goudie et al. stated that because of visual and tactile realism, students can apply basic sewing techniques on these materials as if they were on actual anatomical dimensions. They also remarked that besides gynecology skill trainings, these models can be easily used in patient trainings as well [19]. 

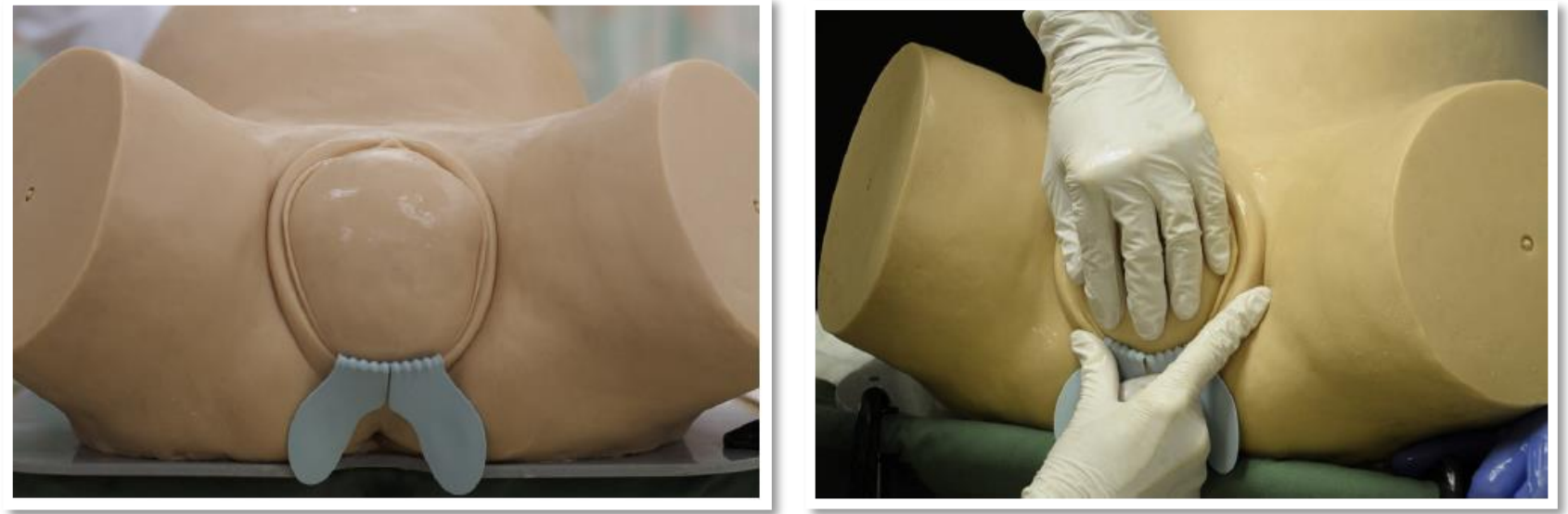

Figure 4. An innovative model used to protect the perineum from lacerations

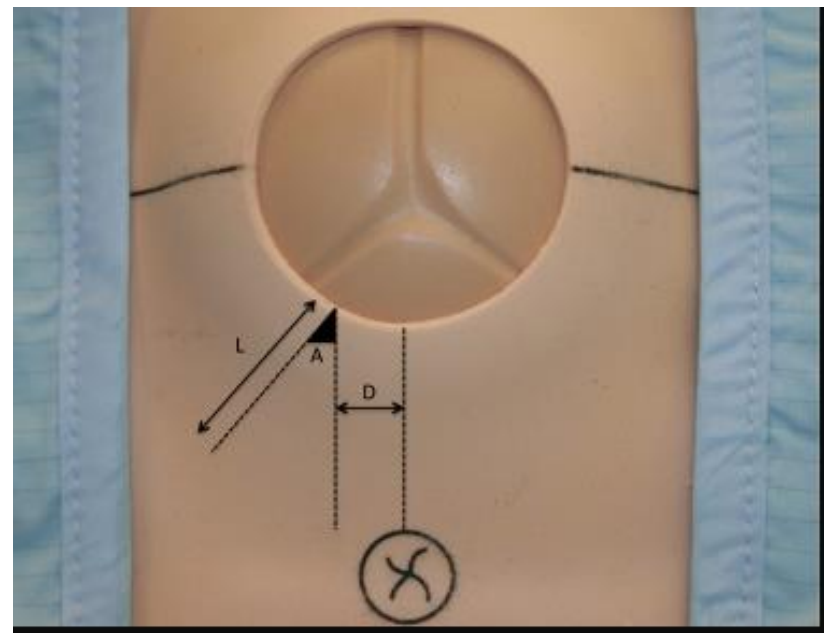

Figure 5. An innovative model used to teach the right method of mediolateral episiotomy to obstetricians and midwives

Another one of the innovative products developed by using thermoplastic material to prevent lacerations during vaginal births has been produced in Sweden. Product developed as nails and wings (Figure 4). It is placed on the posterior vaginal wall during crowning. The maximum tissue thickness of the product is $0.75 \mathrm{~mm}$ and the portion attached to the mouth of the vagina is $47 \mathrm{~mm}$ and the wing parts outside the vagina are $76 \mathrm{~mm}$.

The material was used on 1148 women who had vaginal delivery. In the randomized controlled study, it was observed that the incidence of first and second degree perineal laceration was significantly reduced in the intervention group compared to the control group. In addition, no adverse effects on the mother or baby were reported during the use of the product [22].

In another study was conducted with pad tissue made by synthetic tissue by obstetricians and midwives. They were asked to perform mediolateral episiotomy incision to a stretched perineum during the crowning stage and the incisions made by the practitioners were evaluated with four parameters such as length, angle and shape of the incision
(Figure 5). Of the 197 participants, 16\% stated that they had never received perineal repair training before, $37 \%$ stated that they received one-to-one training previously and 30\% stated that they had group training and at the end of the study, $12.7 \%$ were able to perform incision in accordance with the technique. The participants indicated that trainings with these materials were important in replenishing the professional skills [23].

\section{RESULT}

Attainment of clinical experience with materials closest to human tissue and anatomical structure before contacting real patients by individuals who are responsible for intervening in PTs associated with vaginal birth may reduce PTs. It can make interventions more effective. Such practices play an important role in the acquisition of cognitive and psychomotor skills. It is thought that more frequent use of high-quality, low-cost and easy-to-access training materials in both undergraduate and in-service trainings will provide new and effective learnings without patient rigidity. As more evidence-based results would support the dissemination of training with such materials, it is recommended to carry out studies involving cost analysis.

Declaration of interest: The authors report no conflicts of interest.

Financial Disclosure: No financial support was received.

\section{REFERENCES}

1. Esteban BMM, Calvo JAS, Morcillo CT, Espeja JJD, Hinojosa JG, Goñi ÁZ. Retrospective case review of combined local mepivacaine and steroid injections into vaginal trigger points for the management of moderateto-severe perineal pain after childbirth. Arc. of Gynec. Obs., 2019;299:501-5.

2. Aigmueller $\mathrm{T}$, Bader $\mathrm{W}$, Beilecke $\mathrm{K}$, Elenskaia $\mathrm{K}$, Frudinger A, Hanzal E. Kropshofer S. Management of 3rd and 4th Degree Perineal Tears after Vaginal Birth. German Guideline of the German Society of Gynecology and Obstetrics, 2015;137-44. 
3. Wiseman O, Rafferty AM, Stockley J, Murrells T, Bick D. Infection and wound breakdown in spontaneous second-degree perineal tears: An exploratory mixed methods study. Birth, 2019;1:80-9.

4. Masoumeh AK, Ahmad T, Zohreh S, Elaheh M. Perineal Trauma Incidence and its risk factors. J Obstet Gynaecol., 2019;39:206-11.

5. Kalichman L. Perineal massage to prevent perineal trauma in childbirth. Israel Medical Association Journal. 2008;10:531-3.

6. Bick DE, Kettle C, Macdonald S, Thomas PW, Hills RK, Ismail KM. Perineal assessment and repair longitudinal study (PEARLS): Protocol for a matched pair cluster trial. BMC Pregnancy Childbirth, 2010;1:10.

7. Begley C, Guilliland K, Dixon L, Reilly M, Keegan C, Mc Cann C, Smith V. A qualitative exploration of techniques used by expert midwives to preserve the perineum intact. Women and Birth, 2019;31:87-97.

8. Brunstad A, Nilsen ABV, Aasheim V. Delivery Practices and Perineal Tears: Midwives' Experiences, 2015.

9. Thiessen K, Nickel N, Prior H, Banerjee A, Morris M, Robinson K. Maternity Outcomes in Manitoba Women: A Comparison between Midwifery-led Care and Physician-led Care at Birth. Birth, 2016;43:108-14.

10. Adler B, Bodner A, Oliver K, Julia G, Peter H, Klaus B. A ten-year study of midwife-led care at an Austrian tertiary care center: a retrospective analysis with special consideration of perineal trauma. BMC Pregnancy and Childbirth, 2017;17:2-7.

11. O'Kelly SM, Moore ZE. Antenatal Maternal Education For İmproving Postnatal Perineal Healing for Women who have birthed in Hospital Setting. Cochrane Database of Systematic Reviews, 2017;12.

12. Doo DW, Powell M, Novetsky A, Sheeder J, Guntupalli SR. Preparedness of Ob/Gyn residents for fellowship training in gynecologic oncology. Gynecol Oncol Case Rep., 2015;12:55-60.

13. Şendir M. Use of Simulation in Women Health Nursing Education. F. N. Nurs. J., 2013;21:2147-4923.
14. Akalını A. Şahin S. Theories in Simulation-Based Nursing Education. Journal of Health Science and Profession, 2019;1:135-41.

15. Illston JD, Ballard AC, Ellington DR, et al. Modified Beef Tongue Model for Fourth-Degree Laceration Repair Simulation. Obstet Gynecol., 2017;129:491-6.

16. Sparks RA, Beesley AD, Jones AD. The "sponge perineum:" an innovative method of teaching fourthdegree obstetric perineal laceration repair to family medicine residents. Fam Med., 2006;38:542.

17. Ciesielski P, Małgorzata K, Paweł D. New porcine model of perineal tear and its utility in physicians' training on the reconstruction of $3 \mathrm{rd}$ and 4 th degree perineal tear during vaginal delivery. Ginekol Pol., 2018;10:558-62.

18. Guler H, Cetin P, Yurtsal Z.B, Cesur B, Bekar M, Uçar, et al. Effect of episiotomy training with beef tongue and sponge simulators on the self-confidence building of midwifery students. Nurse Education in Practice. 2018;30;1-6.

19. Goudie C, Shanahan J, Gill A, Murphy D, Dubrowski A. Investigating the efficacy of anatomical silicone models developed from a 3D printed mold for perineal repair suturing simulation. Cureus, 2018;10:8.

20. Berman B. 3-D Printing: The New Industrial Revolution. Business Horizons, 2012;55:155-62.

21. Bartellas MP. Three-dimensional printing and medical education: a narrative review of the literature. University of Ottawa Journal of Medicine, 2016;6:38-43.

22. Lavesson T, Griph I. D, Skärvad A, Karlsson AS, Nilsson HB, Steinvall M, Haadem K. A perineal protection device designed to protect the perineum during labor: a multicenter randomized controlled trial. European Journal of Obstetrics \& Gynecology and Reproductive Biology, 181(2014):10-4.

23. Silf K, Woodhead N, Kelly J, Fryer A, Kettle C, Ismail KMK. Evaluation of accuracy of mediolateral episiotomy incisions using a training model. Midwifery, 2015;31:197-200. 